\title{
Vitamin $K$ status of older individuals in northern China is superior to that of older individuals in the UK
}

\author{
Liya Yan $^{1 *}$, B. Zhou ${ }^{2}$, David Greenberg ${ }^{1,3}$, Laura Wang ${ }^{1}$, Shailja Nigdikar ${ }^{1}$, Celia Prynne ${ }^{1}$ and \\ Ann Prentice ${ }^{1}$ \\ ${ }^{1}$ Medical Research Council Human Nutrition Research, Elsie Widdowson Laboratory, Fulbourn Road, Cambridge CB1 9NL, \\ $U K$ \\ ${ }^{2}$ Department of Preventive Medicine, Shenyang Medical College, 146 Huanghe North Street, Shenyang, 110034, PR China \\ ${ }^{3}$ NHSU Learning Needs Observatory, Victoria House, Capital Park, Fulbourn, Cambridge CB1 5XB, UK
}

(Received 26 January 2004 - Revised 13 July 2004 - Accepted 19 July 2004)

\begin{abstract}
To explore whether differences in vitamin $\mathrm{K}$ nutrition might, at least in part, underlie differences in fracture incidence between Asian and European populations, the vitamin K status of older individuals in Shenyang, China (eighty-six men, ninety-two women) and in Cambridge, UK (sixty-seven men, sixty-seven women) was compared. Dietary information was collected by food questionnaire in Shenyang and food diary in Cambridge and used to estimate the intake and sources of phylloquinone. Fasting blood was analysed for phylloquinone, triacylglycerol, total osteocalcin (tOC) and undercarboxylated osteocalcin (expressed as percentage of tOC; \%ucOC). The mean intakes of green leafy vegetables were 127 (SD 90) g/d in Shenyang and 39 (SD 48) g/d in Cambridge. The estimated phylloquinone intakes (geometric means) were 247 (95\% CI 226, 270) $\mu \mathrm{g} / \mathrm{d}$ in Shenyang and 103 (95\% CI 94, 112) $\mu \mathrm{g} / \mathrm{d}$ in Cambridge. Plasma phylloquinone concentrations (geometric means) were significantly higher in the Shenyang subjects $(2.17$ (95\% CI 1.95, 2.42) nmol/l) than in the Cambridge subjects $(0.69$ (95\% CI $0.63,0.76) \mathrm{nmol} / \mathrm{l} ; P<0.001)$. Plasma phylloquinone concentration was positively related to phylloquinone intake in both the Shenyang (coefficient 0.17 (SE 0.08); $P=0.03$ ) and Cambridge subjects (coefficient 0.29 (SE 0.10); $P=0.005$ ). tOC concentration and \%ucOC (after adjusting for tOC) were significantly lower in the Shenyang than in the Cambridge subjects (tOC 25.2 (SE 4.2) \% and \%ucOC 68.5 (SE 10.0) \% lower respectively; $P<0.001$ ). After adjusting for tOC and triacylglycerol, \%ucOC was negatively related to plasma phylloquinone concentration in both the Shenyang (coefficient $-0 \cdot 41$ (SE $0 \cdot 11$ ); $P=0 \cdot 0003$ ) and Cambridge subjects (coefficient -0.17 (SE 0.07); $P=0.02$ ). The present study demonstrates that older individuals in northern China have a better vitamin $\mathrm{K}$ status compared with their British counterparts in Cambridge, UK.
\end{abstract}

Phylloquinone: Undercarboxylated osteocalcin: China: UK

There is growing evidence that vitamin $\mathrm{K}$ is important to bone health through the vitamin K-dependent $\gamma$-carboxylation of the bone protein osteocalcin (Binkley \& Suttie, 1995). Although the precise role of osteocalcin and the importance of carboxylated osteocalcin in bone physiology is not fully understood, high vitamin $\mathrm{K}$ intakes have been associated with greater bone mineral status in older individuals (Booth et al. 2003). Also, low concentrations of vitamin $\mathrm{K}$ and high proportions of osteocalcin in the undercarboxylated form (\%ucOC) in the circulation have been linked to an increased risk of hip fracture (Feskanich et al. 1999; Booth et al. 2000). In addition, \%ucOC and vitamin $\mathrm{K}$ intake have also been shown to predict the risk of hip fracture independently of bone mineral density in older individuals (Vergnaud et al. 1997; Booth et al. 2000).
The incidence of hip fracture in Shenyang and other regions of China is low compared with that in Western countries (Xu et al. 1996; Yan et al. 1999; Zhang et al. 2000). The predominant form of dietary vitamin K, phylloquinone, is concentrated in green vegetables and certain vegetable oils, such as soyabean oil (Booth et al. 1995a; Bolton-Smith et al. 2000). There is evidence that vegetables may be consumed in greater amounts in China than in the UK (Tian et al. 1995; Finch et al. 1998). There was also a suggestion from a small preliminary study that the vitamin $\mathrm{K}$ status of older women may be better in China than in the UK (Beavan et al. 1997). The aim of the present study was to characterise the vitamin $\mathrm{K}$ status of older individuals in Shenyang, northern China, and Cambridge, UK by investigating the phylloquinone intakes, plasma phylloquinone concentrations and \%ucOC of the two populations.

\footnotetext{
Abbreviations: EI, energy intake; HNR, Human Nutrition Research; tOC, total osteocalcin; ucOC, undercarboxylated osteocalcin; \%ucOC, undercarboxylated osteocalcin expressed as percentage of total osteocalcin.

* Corresponding author: Dr Liya Yan, fax +44 1223 437515, email liya.yan@mrc-hnr.cam.ac.uk
} 


\section{Subject and methods}

\section{Subjects}

The present study was part of an ongoing study on ethnic differences in vitamin $\mathrm{K}$ and $\mathrm{D}$ status and bone health in older Chinese and British adults aged 60-83 years conducted collaboratively by MRC Human Nutrition Research (HNR), Cambridge, UK and Shenyang Medical College, Shenyang, China. An investigation of diet, lifestyle, blood indices of vitamin $\mathrm{K}$ and $\mathrm{D}$ status, markers of $\mathrm{Ca}$ and bone metabolism and bone mineral status at the hip was made in both study populations. Shenyang is one of the largest cities in north-eastern China, as detailed previously (Yan et al. 1999, 2000). There are three main regions; factory, university and commercial in the inner area of the city. Chinese subjects in the present study (eighty-six men and ninety-two women) were recruited by presentations at work units in the factory and university regions. The Cambridge subjects (sixty-seven men and sixty-seven women) were recruited by advertisements in general practice surgeries in Cambridge. Exclusion criteria were pathological disorders or medications known to alter $\mathrm{Ca}$ or bone metabolism such as thyroid disorder, diabetes, cancer, clotting disorder, liver and renal diseases and steroid use. Ethical approval for the Shenyang study was given by the Academic Committee of Shenyang Medical College and for the Cambridge study by the Cambridge Local Research Ethics Committee. All participants provided informed written consent.

To investigate seasonal change in vitamin D status, the present study was conducted in winter (February and March) and summer (August and September) with each subject participating in only one occasion. With the exception of plasma 25-hydroxyvitamin $\mathrm{D}$, there was no seasonal difference in any biochemical markers used in the present study. Plasma 25-hydroxyvitamin D concentrations were lower in winter than in summer in both the Shenyang and Cambridge subjects but the seasonal differences had no effects on plasma total osteocalcin (tOC) or undercarboxylated osteocalcin (ucOC) concentration. Therefore, the comparisons in vitamin K status between the Shenyang and Cambridge subjects were made using the data collected in both seasons. There were a total of 312 subjects; ninety-two Shenyang subjects and sixty-three Cambridge subjects were studied in winter, and eightysix Shenyang subjects and seventy-one Cambridge subjects were studied in summer.

\section{Dietary assessment and phylloquinone intake}

Individuals in Shenyang buy their food by weight from open street markets. A food questionnaire with special emphasis on vitamin K-rich foods was designed to obtain dietary information by asking about all foods purchased over the previous $7 \mathrm{~d}$. The food questionnaire was composed of fifty-eight items from seven food groups: green leafy vegetables; other vegetables (excluding potatoes); cooking fats; fruits; meat, fish and eggs; dairy products; cereals and others. Green leafy vegetables included spinach, rape leaf, broccoli, cabbage, Brussels sprouts, coriander, chives, Chinese leaves, spring onion and lettuce.
In addition to which foods, and how much were purchased, information was also obtained about the number of individuals who then consumed those foods so that the food intake of the participant could be calculated. To obtain energy and nutrient intakes, data were coded and analysed using a nutrient analysis program (LKAT 1998; Shuzhou Medical College, Suzhou, China) in Shenyang Medical College. As currently there is no vitamin $\mathrm{K}$ composition database for food produce in China, the phylloquinone intakes of the Shenyang subjects were estimated using the UK database of phylloquinone content of foods (see later).

The dietary intake of the Cambridge subjects was obtained by a $7 \mathrm{~d}$ food diary in which portion sizes were matched against photographs and quantities described in household measures (Price et al. 1995). The food records were coded into a computer program (DIDO at HNR; Price et al. 1995). The coded records were analysed using an in-house suite of programs based on the 5th edition of McCance and Widdowson's Food Composition Tables (Holland et al. 1991), which also included phylloquinone content (Bolton-Smith et al. 2000; $\mathrm{C}$ Bolton-Smith and M Shearer, unpublished results).

All dietary information was checked to see if any of the volunteers had under- or over-reported their energy intake (EI). This was carried out by calculating the reported EI:BMR ratio. The latter was calculated using the equations described in the report by the UK Department of Health (1991). The mean EI:BMR of the Shenyang men and women were 1.58 (SD 0.35) and 1.78 (SD 0.45) respectively and were within the expected ranges (1.54-1.66 for men and 1.74-1.86 for women) for a moderately physically active population (frequent stair climbing, cycling, walking with loads and manual housework) (Black, 2000). One female subject with an EI:BMR value of 3.2 and with little evidence of physical activity was regarded as having over-reported and was excluded from further analysis. The mean EI:BMR of the Cambridge men and women were 1.44 (SD 0.27) and 1.39 (SD 0.28) respectively and were close or within the expected ranges (1.45-1.55 for men and 1.35-1.45 for women) for a less physically active population (getting about by car and doing little manual housework) (Black, 2000). None of the subjects in Cambridge had an EI:BMR value that was unrealistic.

Because the dietary information for the two population groups was collected by two different methods, it is not appropriate to compare the data directly between the two populations. The food and phylloquinone intakes of the Shenyang and Cambridge subjects therefore will be described qualitatively in the results section with no direct statistical comparisons made.

\section{Biochemical analyses}

Overnight fasted blood samples were collected into EDTAcontaining tubes between 07.00 and 09.00 hours during the week the dietary information was recorded. Plasma was separated from blood cells by a refrigerated centrifuge and stored at $-80^{\circ} \mathrm{C}$ until analysis. Shenyang samples were transported on dry ice to HNR in Cambridge. 


\section{Plasma phylloquinone and triacylglycerol}

Plasma phylloquinone concentration was measured using a modification of the procedure described by Davidson \& Sadowski (1997). Phylloquinone compounds were isolated from $0.25 \mathrm{ml}$ plasma by liquid-liquid extraction, followed by solid-phase extraction $(500 \mathrm{mg}$ silica SEP-PAK cartridge; Waters Corporation, Milford, MA, USA). The vitamin K-rich fraction was analysed by reversed-phase HPLC with post-column reduction ( $\mathrm{Zn}$ dust; SigmaAldrich, St Louis, MO, USA) and fluorimetric detection (Waters 474; Waters Corporation, Milford, MA, USA). An internal standard of vitamin $\mathrm{K}_{1(25)}$ (a synthetic homologue of vitamin $\mathrm{K}_{1}$; Immundiagnostik AG, Germany) was used to compensate for losses of phylloquinone during the extraction process and subsequent chromatographic procedures. The detection limit for this assay was $2.0 \mathrm{pg}$ injection and the quantification limit for $0.25 \mathrm{ml}$ plasma was $0.04 \mathrm{nmol} / 1$

To ensure the quality assurance in routine analysis, three plasma pools containing three different levels of phylloquinone, $0.4,1.4$ and $3.4 \mathrm{nmol} / 1$, were prepared as the quality-control samples. The intra-assay $\mathrm{CV}$ were $5 \cdot 2$, 8.2 and $3.0 \%$, and the inter-assay CV were 16, 12 and $8.1 \%$ respectively. HNR is one of participants in the Vitamin K External Quality Assurance Scheme run by the vitamin K Research and Diagnostic Unit, the Centre for Haemostasis and Thrombosis, St Thomas' Hospital, London. The Vitamin K External Quality Assurance Scheme evaluates the accuracy and precision of the present assay for plasma phylloquinone analyses three times annually.

Plasma triacylglycerol concentration was measured by a colorimetric method (Thermo Clinical Labsystems Oy, Espoo, Finland). The intra- and inter-assay CV were 1.3 and $5.0 \%$ respectively.

\section{Osteocalcin and undercarboxylated osteocalcin}

Plasma tOC and ucOC were analysed by one-step ELISA (Nordic Bioscience Diagnostics A/S, Herlev, Denmark). This assay measures intact osteocalcin and the large N-terminal-mid molecule fragment. The intra- and interassay CV for tOC were 4.1 and $10.5 \%$ respectively. ucOC was measured by treating $60 \mu \mathrm{l}$ of plasma samples with $30 \mu \mathrm{l}$ hydroxyapatite $(15 \mathrm{mg} / \mathrm{ml})$ (Calbiochem, Merck Biosciences) in Eppendorf tubes. These tubes were shaken for $1 \mathrm{~h}$ at room temperature and then centrifuged for $5 \mathrm{~min}$. ucOC in the supernatant fractions was quantified using the same assay kit. The intra- and interassay CV were 15.9 and $14.3 \%$ respectively. The detection limit for the hydroxyapatite-treated sample was $0 \cdot 18 \mu \mathrm{g} / \mathrm{l}$. ucOC concentrations were undetectable in the samples from nineteen Chinese subjects. This was probably due to a combination of very low tOC (mean tOC concentration for the nineteen samples was $8.4 \mu \mathrm{g} / \mathrm{l}$ ) and very low ucOC concentrations in those samples. A nominal concentration of $0.09 \mu \mathrm{g} / \mathrm{l}$ was assigned for the nineteen Chinese samples. The ucOC was expressed as the percentage of total osteocalcin (\%ucOC).

\section{Data analysis}

Statistical analysis was performed by linear model software in Data Desk 6.1.1 (1995; Data Descriptions, Ithaca, NY, USA). To correct for skewed distributions and to permit the exploration of proportional relationships, all continuous variables except age were converted to natural logarithms. Multiple linear regression and analysis of covariance were used to examine the relationships among phylloquinone intake, plasma biochemical markers, age, sex and country and to examine the differences between sex and populations. In natural logarithms, group differences $\times 100$ correspond closely to percentage differences calculated as (difference/mean) $\times 100$ (Prentice et al. 1991). All statistical models were set up in the same way, i.e. full models were generated and then variables $P>0.05$ were removed by backward elimination to provide a parsimonious model.

\section{Results}

The Shenyang women were slightly younger than the Shenyang men and the Cambridge women $(P<0.001)$ (Table 1). The Shenyang men and women were significantly shorter and lighter than their Cambridge counterparts $(P<0 \cdot 001)$.

\section{Food pattern}

To explore dietary patterns and to define the main sources of phylloquinone, the foods consumed by the Shenyang and Cambridge subjects were divided into seven groups in Tables 2 and 3. It is necessary to point out that results itemised under cooking fats used in Shenyang and Cambridge were different. This is because the Shenyang subjects consumed mainly home-prepared food. The fats used for cooking therefore could be itemised, whereas the Cambridge subjects consumed less home-prepared food but a significant amount of processed food bought from the supermarkets. The type and amount of fat added to those processed foods could not be recorded separately but were included in these food categories. Cooking fats in Shenyang were mainly soyabean oil whereas those in Cambridge were vegetable oil, margarine and butter.

The Shenyang subjects had much higher intakes of green leafy vegetables, other vegetables, fruits and cereals in comparison with the Cambridge subjects (Tables 2 and 3 ); the Cambridge subjects consumed more dairy products and meat, fish and eggs. The cereals consumed in Shenyang were mainly rice and wheat flour, whereas those in Cambridge were mainly cereal-based processed foods such as breakfast cereals, bread, scones, muffins, custard and pasta. These cereal-based foods contained some fat added during processing.

\section{Phylloquinone intake}

The mean estimated phylloquinone intake (geometric mean) was 247 (95\% CI 226, 270) $\mu \mathrm{g} / \mathrm{d}$ in the Shenyang subjects (Table 2). None of the Chinese subjects had a phylloquinone intake that was lower than $70 \mu \mathrm{g} / \mathrm{d}$, equivalent to the British safe and adequate intake of $1 \mu \mathrm{g} / \mathrm{kg}$ body 
Table 1. Subject characteristics and plasma biochemical markers of vitamin $\mathrm{K}$ status in older individuals in Shenyang and Cambridge

(Mean values and standard deviations)

\begin{tabular}{|c|c|c|c|c|c|c|c|c|}
\hline & \multicolumn{4}{|c|}{ Chinese } & \multicolumn{4}{|c|}{ British } \\
\hline & \multicolumn{2}{|c|}{ Men $(n 86)$} & \multicolumn{2}{|c|}{ Women (n 92) } & \multicolumn{2}{|c|}{ Men (n 67) } & \multicolumn{2}{|c|}{ Women (n 67) } \\
\hline & Mean & SD & Mean & SD & Mean & SD & Mean & SD \\
\hline Age (years) & $66 \cdot 9$ & $4 \cdot 7$ & $64 \cdot 4^{*}$ & $4 \cdot 4$ & $68 \cdot 8$ & $6 \cdot 0$ & 67.9†† & 6.5 \\
\hline Weight (kg) & $68 \cdot 8$ & $9 \cdot 5$ & $59 \cdot 9^{\star \star}$ & $10 \cdot 5$ & 78.8†† & $9 \cdot 6$ & $69 \cdot 5^{\star \star}+†$ & $12 \cdot 2$ \\
\hline Height (m) & 1.669 & 0.062 & $1.551^{\star \star}$ & 0.053 & $1.734 † \dagger$ & 0.063 & $1.597^{\star \star}+\dagger$ & 0.071 \\
\hline \multicolumn{9}{|l|}{ Phylloquinone (nmol/l) } \\
\hline Geometric mean & $1 \cdot 88$ & & $2 \cdot 48^{\star}$ & & 0.66 十七 & & $0.73+\dagger$ & \\
\hline $95 \% \mathrm{Cl}$ & 1.61 & $2 \cdot 19$ & $2 \cdot 14$ & $2 \cdot 88$ & 0.57 & 0.75 & 0.64 & 0.84 \\
\hline Triacylglycerol (mmol/l) & 1.25 & 0.70 & $1 \cdot 63^{\star \star}$ & 0.80 & $1 \cdot 12$ & 0.51 & $1 \cdot 31^{*}+$ & 0.59 \\
\hline $\mathrm{tOC}(\mu \mathrm{g} / \mathrm{l})$ & 13.9 & $5 \cdot 9$ & $19 \cdot 0^{\star \star}$ & $6 \cdot 1$ & $18 \cdot 2 \dagger+$ & $7 \cdot 3$ & $24 \cdot 5^{\star \star}$ †† & $10 \cdot 8$ \\
\hline $\mathrm{ucOC}(\%$ of $\mathrm{tOC})$ & $13 \cdot 3$ & $9 \cdot 1$ & $22 \cdot 8^{\star \star}$ & 9.9 & $31.6 \dagger+$ & $12 \cdot 9$ & $32 \cdot 7 \dagger \dagger$ & 9.5 \\
\hline
\end{tabular}

tOC, total osteocalcin; ucOC, undercarboxylated osteocalcin.

Mean value was significantly different from that for men in the same population: ${ }^{\star} P<0.05,{ }^{\star \star} P<0.01$.

Mean value was significantly different from that for the Chinese counterparts: $\uparrow P<0.05, \uparrow \uparrow P<0.01$.

weight (Department of Health, 1991). The mean phylloquinone intake (geometric mean) was 103 (95\% CI 94, 112) $\mu \mathrm{g} / \mathrm{d}$ in the Cambridge subjects (Table 3); $22 \%$ of these subjects had an intake below $70 \mu \mathrm{g} / \mathrm{d}$.

The main sources of phylloquinone intake in Shenyang were green leafy vegetables, other vegetables and soyabean oil (Table 2). Green leafy and other vegetables were also the main sources of phylloquinone intake in Cambridge (Table 3). Cereal-based food was the next highest contributor in Cambridge due to the fats contained in those foods.

\section{Plasma phylloquinone}

The mean plasma phylloquinone concentration was significantly higher in the Shenyang men and women than in the Cambridge men and women $(P<0.001)$ (Table 1). On average, there was a 3-fold difference between the two populations (geometric mean 2.17 (95\% CI 1.95, 2.42) $v$. geometric mean 0.69 (95\% CI 0.63, 0.76) nmol/1).
Plasma triacylglycerol concentration was significantly higher in the Shenyang women compared with the Cambridge women (19.8 (SE 7.6) \% higher; $P=0.01$ ) (Table 1). It was also higher in the Cambridge women compared with the Cambridge men (15.8 (SE 6.9) \% higher; $P=0.02$ ) and in the Chinese women compared with the Shenyang men (27.2 (SE 7.8) \% higher; $P=0.0007$ ). Phylloquinone concentration was positively related to triacylglycerol concentration in the Shenyang subjects (coefficient 0.65 (SE 0.09); $P=0.0001$ ) but not in the Cambridge subjects (coefficient $0.04(\operatorname{SE~} 0.12) ; P=0.75$ ) and this relationship differed significantly between Shenyang and Cambridge $(P=0.0001)$. Plasma phylloquinone concentration was negatively associated with age, independent of triacylglycerol concentration, in the Shenyang subjects $(P=0.01)$ but not in the Cambridge subjects.

Plasma phylloquinone concentration was higher in the Shenyang women than in the Shenyang men (29.5 (SE 10.7) $\%$ higher; $P=0.006$ ). There was no difference

Table 2. Phylloquinone intake and sources in Shenyang subjects* (Mean values and standard deviations)

\begin{tabular}{|c|c|c|c|c|c|}
\hline & \multicolumn{2}{|c|}{ Food intake $(\mathrm{g} / \mathrm{d})$} & \multicolumn{2}{|c|}{$\begin{array}{l}\text { Phylloquinone from } \\
\text { food groups }(\mu \mathrm{g} / \mathrm{d})\end{array}$} & \multirow{2}{*}{$\begin{array}{l}\text { Percentage of total } \\
\text { phylloquinone intake }\end{array}$} \\
\hline & Mean & $\mathrm{SD}$ & Mean & SD & \\
\hline Green leafy vegetables & 127 & 90 & 204 & 193 & 68.5 \\
\hline Other vegetables & 234 & 185 & 35 & 40 & 11.7 \\
\hline Cooking fats & 32 & 12 & 39 & 15 & $13 \cdot 1$ \\
\hline Cereal-based foods & 302 & 105 & 5 & 7 & 1.7 \\
\hline Fruits & 351 & 218 & 8 & 8 & $2 \cdot 7$ \\
\hline Meat, fish and eggs & 158 & 76 & 2 & 2 & 0.7 \\
\hline Dairy foods & 155 & 144 & 1 & 1 & 0.3 \\
\hline Other foods & 214 & 137 & 4 & 3 & 1.3 \\
\hline \multicolumn{6}{|l|}{ Vitamin $\mathrm{K}$ intake $(\mu \mathrm{g} / \mathrm{d})$} \\
\hline Arithmetic mean & \\
\hline $95 \% \mathrm{Cl}$ & \multicolumn{5}{|c|}{270,326} \\
\hline Geometric meant & \multirow{2}{*}{\multicolumn{5}{|c|}{$\begin{array}{c}247 \\
226,270\end{array}$}} \\
\hline $95 \% \mathrm{Cl}$ & & & & & \\
\hline
\end{tabular}

* Vitamin K intake was assessed by food questionnaire ( $n$ 177).

† Antilog of $\log _{\mathrm{e}}$-transformed data. 
Table 3. Phylloquinone intake and sources in Cambridge subjects*

(Mean values and standard deviations)

\begin{tabular}{|c|c|c|c|c|c|}
\hline & \multicolumn{2}{|c|}{ Food intake $(\mathrm{g} / \mathrm{d})$} & \multicolumn{2}{|c|}{$\begin{array}{l}\text { Phylloquinone from } \\
\text { food groups }(\mu \mathrm{g} / \mathrm{d})\end{array}$} & \multirow{2}{*}{$\begin{array}{l}\text { Percentage of total } \\
\text { phylloquinone intake }\end{array}$} \\
\hline & Mean & SD & Mean & SD & \\
\hline Green leafy vegetables & 39 & 48 & 59 & 67 & $50 \cdot 4$ \\
\hline Other vegetables & 144 & 74 & 17 & 14 & 14.5 \\
\hline Cooking fats & 17 & 10 & 3 & 3 & $2 \cdot 6$ \\
\hline Cereal-based foods & 262 & 96 & 11 & 7 & 9.4 \\
\hline Fruits & 188 & 122 & 6 & 6 & $5 \cdot 1$ \\
\hline Meat, fish and eggs & 195 & 76 & 7 & 7 & $6 \cdot 0$ \\
\hline Dairy foods & 368 & 212 & 2 & 1 & 1.7 \\
\hline Other foods & 184 & 84 & 12 & 8 & $10 \cdot 3$ \\
\hline \multicolumn{6}{|l|}{ Vitamin $K$ intake $(\mu \mathrm{g} / \mathrm{d})$} \\
\hline Arithmetic mean & \multirow{2}{*}{\multicolumn{5}{|c|}{$\begin{array}{c}117 \\
105 \quad 129\end{array}$}} \\
\hline $95 \% \mathrm{Cl}$ & & & & & \\
\hline Geometric mean $\dagger$ & \multirow{2}{*}{\multicolumn{5}{|c|}{$\begin{array}{c}103 \\
94.112\end{array}$}} \\
\hline $95 \% \mathrm{Cl}$ & & & & & \\
\hline
\end{tabular}

*Vitamin $\mathrm{K}$ intake was assessed by $7 \mathrm{~d}$ food diary ( $n$ 134).

† Antilog of $\log _{\mathrm{e}}$-transformed data.

between the sexes in Cambridge. After adjusting for triacylglycerol concentration and age, the difference in plasma phylloquinone concentration between the Shenyang men and women was no longer significant (7.2 (SE 10.2) \%; $P=0.50)$.

Plasma phylloquinone concentration was positively related to phylloquinone intake in both the Shenyang (coefficient 0.18 (SE 0.09); $P=0.04$ ) and Cambridge subjects (coefficient 0.29 SE $0 \cdot 10$ ); $P=0.005$ ) (Fig. 1). This association changed little after adjusting for triacylglycerol concentration and age in the Shenyang subjects (coefficient 0.17 (SE 0.08); $P=0.03$ ).

There was a weak positive association between plasma phylloquinone concentration and leafy vegetable intake after adjusting for plasma triacylglycerol concentration and age in the Shenyang subjects (coefficient 0.11 (SE $0.05) ; P=0.05$ ). A tendency towards a positive association between phylloquinone concentration and green leafy intake was also found in the Cambridge subjects (coefficient $0 \cdot 10$ (SE 0.05); $P=0 \cdot 06$ ).

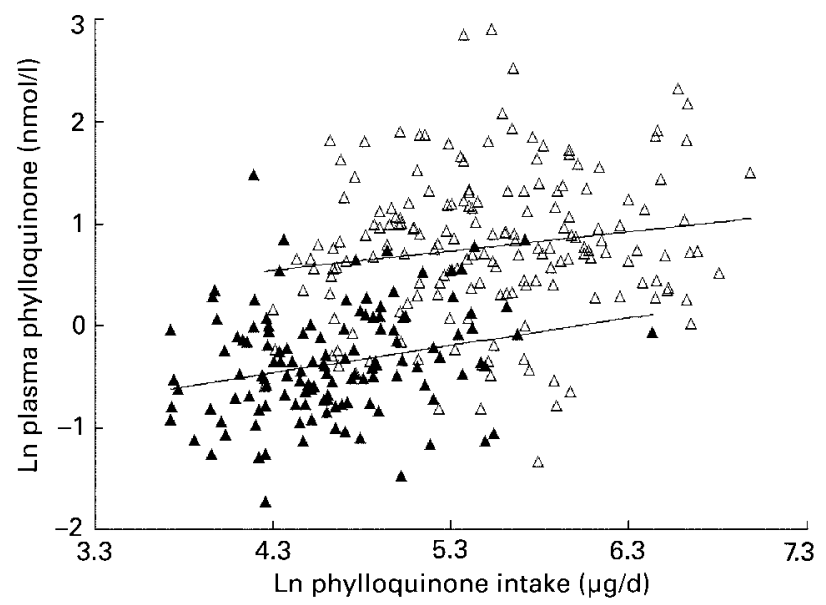

Fig. 1. The relationship of phylloquinone intake and plasma phylloquinone concentration in Shenyang $(\triangle)$ and Cambridge $(\boldsymbol{\Lambda})$ subjects $(P=0.04$ and $P=0.005$ respectively).

\section{Osteocalcin and percentage of undercarboxylated osteocalcin}

Mean tOC concentration was significantly lower in the Shenyang men and women than in the Cambridge men and women (28.9 (SE 6.0) and 21.6 (SE 5.8) \% lower respectively; $P<0.001$ ) (Table 1). \%ucOC was strongly and positively related to tOC concentration in the Shenyang subjects (coefficient 1.19 (SE 0.20); $P=0.0001)$ but not in the Cambridge subjects (coefficient 0.17 (SE $0 \cdot 10) ; P=0 \cdot 08)$. This relationship was significantly different between the two populations $(P<0 \cdot 0001)$. After adjusting for tOC, \%ucOC was significantly lower in the Shenyang men and women than in the Cambridge men and women (97.6 (SE 16.3) and 40.2 (SE 11.0) \% lower respectively; $P<0.001)$ (Table 1$)$.

After adjusting for tOC, triacylglycerol and sex, \%ucOC was negatively related to plasma phylloquinone concentration in both the Shenyang subjects (coefficient -0.41 (SE 0.11); $P=0.0003$ ) and in the Cambridge subjects (coefficient -0.17 (SE 0.07); $P=0.02$ ). It was also found that tOC concentration was negatively related to phylloquinone concentration in both the Shenyang subjects (coefficient -0.09 (SE 0.04); $P=0.008$ ) and the Cambridge subjects (coefficient -0.12 (SE 0.06$) ; P=0.05)$. After adjusting for tOC and sex, \%ucOC was negatively related to phylloquinone intake in the Cambridge subjects (coefficient -0.14 (SE 0.07); $P=0.04$ ). A similar but non-significant trend was also found in the Shenyang subjects (coefficient $-0 \cdot 13$ (SE $0 \cdot 10) ; P=0 \cdot 18)$.

\section{Discussion}

Vitamin $\mathrm{K}$ intakes and status of older individuals have been reported in several Caucasian populations (Booth et al. 1995b; Schurgers et al. 1999; McKeown et al. 2002; Thane et al. 2002a) but not in Asian populations, especially in China. The present study has demonstrated that in comparison with their British counterparts in Cambridge, older individuals in Shenyang had a higher 
estimated phylloquinone intake and better vitamin $\mathrm{K}$ status as indicated by their higher plasma phylloquinone concentration and lower \%ucOC. The high phylloquinone intake in Shenyang was due to a higher consumption of vegetables, particularly green leafy vegetables, and soyabean oil, which is high in phylloquinone.

The present study has also demonstrated that in both populations a lower intake of phylloquinone was associated with a lower plasma phylloquinone concentration and a higher \%ucOC. Phylloquinone intake therefore was a determinant of vitamin $\mathrm{K}$ status in Shenyang as well as Cambridge subjects. Green leafy and other vegetables were the main sources of phylloquinone, although intakes were significantly lower in Cambridge. The higher contribution of phylloquinone from cereals in Cambridge was due to the oil and fat added during the production of cereal-based foods, such as bread, scones, muffins, biscuits and cakes.

We have made an effort to assess vitamin $\mathrm{K}$ status in a Chinese population. The dietary assessment in the Chinese study was conducted using a food questionnaire due to limited resources at the time. We are aware of the limitations of food questionnaires in collecting dietary information. However, we found that the food pattern of the Chinese subjects in Shenyang was very similar to that seen in other dietary surveys in northern Chinese populations (Tian et al. 1995), especially in terms of vegetable and oil consumption. This, together with the positive association between plasma phylloquinone concentration and phylloquinone intake, indicates that the dietary information collected by the food questionnaire has, to a certain degree, reflected the habitual dietary pattern of the population.

As phylloquinone is incorporated in chylomicrons following absorption and transported to the liver in the triacylglycerol-rich lipoproteins there is a positive correlation between plasma phylloquinone and triacylglycerol concentrations (Shearer, 1995). However, in the present study a strong positive association between plasma phylloquinone and triacylglycerol concentration was only found in the Shenyang but not in the Cambridge subjects. The strong triacylglycerol $\times$ country interaction in relation to plasma phylloquinone suggests that the relationship may be different between the two populations. However, plasma triacylglycerol concentration has been reported to be positively related to plasma phylloquinone concentration in older Caucasian populations (McKeown et al. 2002; Thane et al. 2002a). We also found that women had higher triacylglycerol concentrations than men both in Shenyang and Cambridge. The reason for this is not yet clear but might relate to differences in dietary habits.

The estimated phylloquinone intake of the older Chinese subjects in the present study was $247 \mu \mathrm{g} / \mathrm{d}$, which is higher than the values of $60-120 \mu \mathrm{g} / \mathrm{d}$ reported in Western countries (Booth et al. 1995b; McKeown et al. 2002; Thane et al. 2002a). However, intakes of over $200 \mu \mathrm{g} / \mathrm{d}$ have been reported in the Dutch population (Jie et al. 1995; Schurgers et al. 1999). The phylloquinone intake of the Cambridge subjects in the present study was higher than those reported in a Scottish population (arithmetic means 69-76 $\mu \mathrm{g} / \mathrm{d}$ ) (Fenton et al. 1997) and in a national survey in British elderly individuals from
London and the south-east of England (geometric means $74-80 \mu \mathrm{g} / \mathrm{d}$ ) (Thane et al. 2002b). This may reflect socio-economic differences in the Cambridge region.

We found that plasma tOC concentration was significantly lower in the Shenyang subjects than in the Cambridge subjects, and there was a strong negative association between plasma tOC and phylloquinone concentrations in the Shenyang subjects. In addition, to a lesser extent, tOC concentration was also negatively related to plasma phylloquinone concentration in the Cambridge subjects. This seems to suggest that a better vitamin $\mathrm{K}$ status may be associated with a lower bone turnover. However, more bone turnover markers need to be studied.

In conclusion, the vitamin $\mathrm{K}$ status of older individuals in northern China, where the incidence of hip fracture is low, is superior to that of older individuals in the UK. These findings support the notion that good vitamin $\mathrm{K}$ status is associated with a decreased risk of hip fractures. The impact of the difference in vitamin $\mathrm{K}$ status on bone mineral status and bone metabolism in the two populations is under investigation.

\section{Acknowledgements}

The present study was supported in part by the Nestlé Foundation, Switzerland. We thank Dr Caroline Bolton-Smith and Dr Martin Shearer for allowing us to use the unpublished database of vitamin K content of foods, Dr Martin Shearer for expert help on phylloquinone analysis, Dr Caren Gundberg for advice on ucOC analysis, and Dr Gail Goldberg for guidance on assessing dietary intake data. We also thank Dr Fiona Ginty, Ms Xiaohong Wang, Mr Songtao Wang, Miss Grace Tan and Ms Janet Bennett for advice and assistance in other aspects of the study. We are grateful to the subjects who took part in Shenyang and Cambridge.

\section{References}

Beavan S, Prentice A, Stirling DM \& Yan L (1997) Differences in undercarboxylated osteocalcin, a marker of vitamin $\mathrm{K}$ status between British and Chinese women. Proc Nutr Soc 57, 72A.

Binkley NC \& Suttie JW (1995) Vitamin K nutrition and osteoporosis. J Nutr 125, 1812-1821.

Black AE (2000) Critical evaluation of energy intake using the Goldberg cut-off for energy intake:basal metabolic rate. A practical guide to its calculation, use and limitations. Int J Obes Relat Metab Disord 24, 1119-1130.

Bolton-Smith C, Price RJG, Fenton ST, Harrington DJ \& Shearer MJ (2000) Compilation of a provisional UK database for the phylloquinone (vitamin K1) content of foods. Br J Nutr 83, 389-399.

Booth SL, Broe KE, Gagnon DR, Tucker KL, Hannan MT, McLean RR, Dawson-Hughes B, Wilson PW, Cupples LA \& Kiel DP (2003) Vitamin K intake and bone mineral density in women and men. Am J Clin Nutr 77, 512-516.

Booth SL, Sadowski JA \& Pennington JAT (1995a) Phylloquinone (vitamin K1) content of foods in the U. S. Food and Drug Administration's total diet study. J Agric Food Chem 43, 1574-1579. 
Booth SL, Sokoll LJ, O’Brien ME, Tucker K, Dawson-Hughes B \& Sadowski JA (1995b) Assessment of dietary phylloquinone intake and vitamin $\mathrm{K}$ status in postmenopausal women. Eur $J$ Clin Nutr 49, 832-841.

Booth SL, Tucker KL \& Chen H et al. (2000) Dietary vitamin K intakes are associated with hip fracture but not with bone mineral density in elderly men and women. Am J Clin Nutr 71, 1201-1208.

Davidson KW \& Sadowski JA (1997) Determination of vitamin K compounds in plasma or serum by HPLC using post-column chemical reduction and fluorimetric detection. In Methods in Enzymology, pp. 408-421 [JN Abelson and MI Simon, editors]. Orlando, FL: Academic Press.

Department of Health (1991) Dietary Reference Values for Food Energy and Nutrients for the United Kingdom. Report of the Panel on Dietary Reference Values of the Committee on Medical Aspects of Food Policy. London: H.M. Stationery Office.

Fenton ST, Price RJ, Bolton-Smith C, Harrington D \& Shearer MJ (1997) Nutrient sources of phylloquinone (vitamin K1) in Scottish men and women. Proc Nutr Soc 56, 301A.

Feskanich D, Weber P, Willett WC, Rochett H, Booth SL \& Colditz GA (1999) Vitamin K intake and hip fractures in women: a prospective study. Am J Clin Nutr 69, 74-79.

Finch S, Doyle W, Lowe C, Bates CJ, Prentice A, Smithers G \& Clarke PC (1998) National Diet and Nutrition Survey: People Aged 65 Years and Over. London: The Stationery Office.

Holland B, Welch AA, Unwin ID, Buss DH, Paul AA \& Southgate DAT (1991) McCance and Widdowson's The Composition of Foods, 5th ed., Cambridge and London: Royal Society of Chemistry and Ministry of Agriculture, Fisheries and Food.

Jie KSG, Bots ML, Vermeer C, Writteman JCM \& Grobbee DE (1995) Vitamin K intake and osteocalcin levels in women with and without aortic atherosclerosis: a population-based study. Atherosclerosis 116, 117-123.

McKeown NM, Jacques PF, Gundberg CM, Peterson JW, Tucker KL, Kiel DP, Wilson PW \& Booth SL (2002) Dietary and nondietary determinants of vitamin $\mathrm{K}$ biochemical measures in men and women. $J$ Nutr 132, 1329-1334.

Prentice A, Shaw J, Laskey MA, Cole TJ \& Fraser DR (1991) Bone mineral content of British and rural Gambian women aged 18-80+ years. Bone Miner 12, 201-214.
Price GM, Paul AA, Key FB, Harter AC, Cole T, Day KC \& Wadsworth MEJ (1995) Measurement of diet in a large national survey: comparison of computerized and manual coding of records in household measures. J Hum Nutr Diet 8, $417-428$.

Schurgers LJ, Geleijnse JM, Grobbee DE, Pols HAP, Hofman A, Witteman JCM \& Vermeer C (1999) Nutritional intake of vitamins $\mathrm{K} 1$ (phylloquinone) and $\mathrm{K} 2$ (menaquinone) in The Netherlands. J Nutr Environ Med 9, 115-122.

Shearer MJ (1995) Vitamin K. Lancet 345, 229-234.

Thane CW, Bates CJ, Shearer MJ, Unadkat N, Harrington DJ, Paul AA, Prentice A \& Bolton-Smith C (2002a) Plasma phylloquinone (vitamin K1) concentration and its relationship to intake in a national sample of British elderly people. $\mathrm{Br} J$ Nutr 87, 615-622.

Thane CW, Paul AA, Bates CJ, Bolton-Smith C, Prentice A \& Shearer MJ (2002b) Intake and sources of phylloquinone (vitamin K1): variation with socio-demographic and lifestyle factors in a national sample of British elderly people. Br J Nutr 87, 605-613.

Tian HG, Nan Y, Hu G, Dong QN, Yang XL, Pietinen P \& Nissinen A (1995) Dietary survey in a Chinese population. Eur J Clin Nutr 49, 26-32.

Vergnaud P, Garnero P, Meunier P, Breart G, Kamihagi K \& Delmas P (1997) Undercarboxylated osteocalcin measured with a specific immunoassay predicts hip fracture in elderly women: the EPIDOS study. J Clin Endocrinol Metab 82, $719-724$.

Xu L, Lu A, Zhao X, Chen X \& Cummings SR (1996) Very low rates of hip fracture in Beijing, People's Republic of China: the Beijing Osteoporosis Project. Am J Epidemiol 144, 901-907.

Yan L, Prentice A, Zhang H, Wang X, Stirling DM \& Golden MM (2000) Vitamin D status and parathyroid hormone concentrations in Chinese women and men from north-east of the People's Republic of China. Eur J Clin Nutr 54, 68-72.

Yan L, Zhou B, Prentice A, Wang X \& Golden MHN (1999) An epidemiological study of hip fracture in Shenyang, P R China. Bone 24, 151-155.

Zhang L, Cheng A, Bai Z, Lu Y, Endo N \& Dohmae Y (2000) Epidemiology of cervical and trochanteric fractures of the proximal femur in 1994 in Tangshan, China. J Bone Miner Metab 18, 84-88. 